\title{
Numerical Method for Fatigue Life Prediction of Liquid-Storage Tank via Crack Length and Depth
}

\author{
Jiafeng Lai, ${ }^{1}$ Ziyun You, ${ }^{2}$ Jiao Luo, ${ }^{2}$ Yuwei Wei, ${ }^{3}$ and Xintian Liu $\mathbb{D}^{2}$ \\ ${ }^{1}$ College of Petroleum and Chemical Engineering, Beibu Gulf University, Qinzhou 535011, China \\ ${ }^{2}$ School of Mechanical and Automotive Engineering, Shanghai University of Engineering Science, Shanghai 201620, China \\ ${ }^{3}$ Guangxi Special Equipment Supervision and Inspection Institute, Nanning 530219, China \\ Correspondence should be addressed to Xintian Liu; xintianster@qq.com
}

Received 11 April 2020; Revised 29 May 2020; Accepted 21 September 2020; Published 12 October 2020

Academic Editor: Guian Qian

Copyright (C) 2020 Jiafeng Lai et al. This is an open access article distributed under the Creative Commons Attribution License, which permits unrestricted use, distribution, and reproduction in any medium, provided the original work is properly cited.

In the field of fatigue crack, crack size is a worthy topic to discuss. The relationship between crack length and depth is studied based on the Paris law, and a numerical model is established. The validity of the model is proved by comparing theoretical data with experimental data. In addition, the analysis of stress distribution of liquid-storage tank is carried out and the influence of hoop stress on the liquid-storage tank is considered. Remaining life of the tank is predicted through the numerical model. The feasibility of the numerical method is verified by predicting the remaining life of the tank, which provides a simple way for fatigue life prediction of the liquid-storage tank.

\section{Introduction}

With the improvement of industrial technology, the liquidstorage tank has gradually become an indispensable large cylindrical container in industrial production. As important storage equipment for chemical raw materials, the safety of storage tanks has been widely concerned. At present, the design of tanks and their components can refer to the design of pressure vessels, which are designed by either elasticbased failure criteria or plastic-based failure criteria $[1,2]$. The structural design of the liquid-storage tank cannot be separated from the combination of engineering and mechanics, which represents the advanced level of the contemporary structural design.

Oil tank is a kind of storage tank. And it is used to store crude oil, gasoline, kerosene, diesel oil, and other petroleum products. Petrochemical plants usually check the oil tanks regularly to ensure safety. The common test methods are the ultrasonic test, magnetic particle test, and penetrant test. The structure of the tank is changing under the pressure from ground, strong wind, and liquids. For example, the tank wall would become thinner, and also the cracks and corrosion defects may appear on the inner wall surface and the bottom plate subsides. At this time, it is necessary to detect the defective parts of the tank to determine whether the tank is still in a safe state. And the corresponding plan needs to be formulated according to the test results. The most commonly used method is stress analysis, which analyzes the maximum stress received by each part of the tank and finds out the dangerous parts and then repairs them. When the stress is within the reasonable stress range, the tank could be continued for safety production. When the stress exceeds the safe range, the tank shall be immediately stopped using or taking other measures to ensure the safety of the tank. There are two aspects in the safety evaluation of tank with defects: residual strength analysis and remaining life prediction. Residual strength analysis is based on the inspection data of pressure vessel, through rigorous theoretical derivation and calculation to get the maximum allowable working pressure of the tank and the critical defect size. Remaining life prediction of pressure vessel with defects is based on fatigue theory and linear elastic fracture mechanics or elastic-plastic mechanics [3-5]. Based on the degradation law of material properties, the critical state is found and the remaining life of the tank is given. The remaining life prediction results can be used as a reference for the safety production of enterprises 
and provide a scientific basis for the formulation of tank inspection period.

In the mechanical structure, fatigue crack will occur under the action of alternating load. For liquid-storage tank, if the crack occurs, the original stress structure of the tank would be damaged. Generally speaking, the crack mainly occurs at the stress concentration center. There are several types of fatigue cracks, such as open crack, split crack, and tear crack. There will be vertical tensile stress on the crack surface of the tank, which results in the existence of open cracks. In this case, the displacement in the crack opening direction is discontinuous. For the split crack, it is mainly to analyze the shear stress of the tank surface. In terms of the factors affecting crack growth and fatigue fracture of the storage tank, the following aspects should be considered. Actually, the members in the engineering practice are subject not only to one load but also to variable amplitude load. In addition, loading frequency is also an influential factor, which is related to the stress intensity factor. If the value of the stress intensity factor is large, the change of loading frequency will have a significant effect on crack growth $[6,7]$. To analyze the crack rule of fatigue fracture for a liquid-storage tank, it is necessary to analyze the transverse fracture pattern and the longitudinal fracture pattern. In general, if there is a transverse crack, it is likely that the internal pressure of the tank is relatively large. In addition to the impact of internal processing materials, it is easy to produce a transverse crack in the tank.

Actually, many scholars have studied the working condition of the liquid-storage tank. Experimental results indicate that the dirty water of the oil tank does not have a remarkable influence on the crack propagation growth rate of the butt joint of $12 \mathrm{MnNiVR}$ [8]. A rotational throughtransmission ultrasonic propagation imaging system is used to inspect the full thickness of the entire cylindrical section of filament-wound composite overwrapped pressure vessels [9]. A mathematical model was introduced that describes all geometry of the physical characteristics of hollow organs behaving as pressure vessels based on the physics of ideal pressure vessels [10]. And a segmented locking ring for shellbottom connection is analyzed [11]. For the safe use of a pressure relief system, some of the parameters are critical, for example, selection of construction materials, sizing of relief valves, temperature, and pressure [12].

The paper is organized as follows: firstly, the characteristics of fatigue crack growth and its influencing factors are represented. Next, it introduces the research status of domestic and foreign researchers with examples and puts forward the research focus of this paper. Then, the relationship model between crack length and depth is established based on the Paris law, and the feasibility of the model is verified by the comparison of theoretical data and experimental data. The remaining life of the storage tank is predicted based on the inspection results. And the theoretical results show that the predicted results are in good agreement with the actual service life.

\section{Methods and Models}

The application of fracture mechanics in fatigue research, especially in the field of fatigue crack growth, has made a great progress. According to the Paris law, the relation between $(\mathrm{d} a / \mathrm{d} N)$ and $K$ can be described as follows:

$$
\frac{\mathrm{d} a}{\mathrm{~d} N}=C(\Delta K)^{m}
$$

It does not describe the $R$-effect on crack growth, neither the asymptotic behavior in regions I and III. Several alternative functions have been proposed in the literature to overcome this problem. For example,

$$
\frac{\mathrm{d} a}{\mathrm{~d} N}=\frac{C(\Delta K)^{m}}{(1-R)\left(K_{c}-K_{\max }\right)} .
$$

Because of the term $\left(K_{c}-K_{\max }\right)$ in the denominator, $(\mathrm{d} a / \mathrm{d} N)$ will become very large if $K_{\max }$ is approaching $K_{c}$. The effect of the stress ratio $R$ is also accounted for by the term $(1-R)$ in the denominator. But the $\Delta K_{\text {th }}$ asymptote is not yet included.

$$
\frac{\mathrm{d} a}{\mathrm{~d} N}=C\left[\frac{\Delta K-\Delta K_{\mathrm{th}}}{K_{c}-K_{\max }}\right]^{m} .
$$

The value of $\Delta K_{\text {th }}$ in such equations is supposed to be a function of $R$ [13]:

$$
\Delta K_{\mathrm{th}}=A(1-R)^{n}
$$

The Paris law is widely used in engineering to describe the fatigue crack growth characteristics of materials $[14,15]$. The fatigue life of mechanical components has been evaluated, which is considered an elasticity-based load spectrum [16]. And a modified quality loss model of service life prediction has been established $[17,18]$. Although the Paris law ignores the influence of the threshold region and the instantaneous fracture region, it is still widely used in engineering structures because of its simplicity.

In equation $(1),(\mathrm{d} a / \mathrm{d} N)$ is the crack growth rate, which refers to the average increment of crack length per cycle. It is a function of crack length, stress amplitude, or strain amplitude, reflecting the fatigue performance of components. The higher the expansion rate, the shorter the fatigue life and the worse the fatigue performance. $C$ and $m$ are the crack growth parameters, which are related to the material. And $\Delta K$ is the range of stress intensity factor. It is defined as

$$
\Delta K=\gamma \Delta S \sqrt{\pi a}
$$

where $\gamma$ is the shape factor, $\Delta S$ is the stress range, and $a$ is the crack length.

$$
\gamma=b_{1}+b_{2}\left(\frac{a}{W}\right)+b_{3}\left(\frac{a}{W}\right)^{2}+b_{4}\left(\frac{a}{W}\right)^{3} .
$$

In the engineering structure, $W$ is the width of the test piece. $b_{i}(i=1,2,3$, and 4$)$ is constant, where $b_{1}=1.12$. 
Generally, the value of $\gamma$ is about 1.12 , and the value of $(a / W)$ is very small.

Integrating equation (1) to obtain crack propagation life

$$
N=\frac{1}{C(\gamma \Delta S \sqrt{\pi})^{m}} \int_{a_{0}}^{a_{c}} \frac{\mathrm{d} a}{a^{(m / 2)}},
$$

where $a_{0}$ is the initial crack size and $a_{c}$ is the critical crack size. Their expressions are as follows:

$$
\begin{aligned}
& a_{0}=\frac{1}{\pi}\left(\frac{K_{\mathrm{IC}}}{\sigma_{b}}\right)^{2}, \\
& a_{c}=\frac{1}{\pi}\left(\frac{K_{\mathrm{IC}}}{\Delta S \times \gamma}\right)^{2} .
\end{aligned}
$$

$K_{\mathrm{IC}}$ is the fracture toughness, which is not related to the shape of the crack or the magnitude of the external stress but an inherent characteristic of the material. Many scholars express the form of surface crack as elliptical or semi-elliptical crack. In order to explore the relationship between crack length and depth, according to reference [19], equation (7) is introduced.

$$
a=0.75\left(a_{b}\right)^{1.43},
$$

where $a_{b}$ is the depth of surface crack, as shown in Figure 1.

In the experimental study of surface crack growth, it is necessary to measure the change of crack depth and the growth of crack in the surface direction at the same time. The surface length of crack can be measured directly by online reading microscope. The depth of the crack is usually measured by the Hook method. After the fracture of the specimen, the size of the crack is measured by the microscope.

In addition to the analysis of elastic fracture mechanics, elastic-plastic fracture mechanics can also be considered. According to the elastic-plastic fracture mechanics, the crack growth rate can be expressed as follows:

$$
\frac{\mathrm{d} a}{\mathrm{~d} N}=C(\Delta \delta)^{m},
$$

where $\delta$ is the crack tip opening displacement and it could be expressed as $\delta=\left(\sigma^{2} \pi a / E \sigma_{\mathrm{s}}\right) . \sigma_{\mathrm{s}}$ is the yield strength of the material.

Elastic-plastic fracture has occurred as the size of plastic zone is close to or significantly larger than the crack size. When the crack opening displacement reaches the critical size, the crack will develop unsteadily.

\section{Analysis of Cases}

3.1. Relationship between Crack Depth and Fatigue Life. In engineering practice, pressure vessels have many failure modes mainly because of decay, fatigue, and vessel wall defects. Therefore, in the process of pressure vessel design and acceptance, it is necessary to carry out specific analysis and amendment according to the strength condition. For example, when the tank has defects, the remaining life of the tank should be estimated according to the fatigue crack growth theory. For the high-temperature pressure vessel, the theoretical strength should be improved. There are many difficulties in the design and life estimation of vessels, which need sufficient theoretical basis and experimental support.

It can be seen from the Paris law that the fatigue life increases with the increase of crack size. Table 1 shows the test data of a tensile rod at different crack depths [20], and Table 2 shows the theoretical life data obtained from equation (7). It can be seen that the data obtained with equation (7) is in good agreement with the test data.

We assume that $a_{b}=0.9^{m} a$ [21], regard it as a linear model, and combine it with equation (7) to get the data in Table 3. Compared with the data in Table 2, the error between test data and data from the linear model is larger.

The data in Tables 1-3 are fitted into curves; as shown in Figure 2, it can be seen that the growth rate of fatigue life slows down with the increase of crack size. The results from the nonlinear model are closer to the experimental results.

3.2. Life Prediction of Liquid-Storage Tank. Under hydrostatic pressure, the storage tank will generate internal stress. Components' self-weight and internal medium mass will cause bending stress or tensile stress and give the support for the reaction that the tank will generate local stress [22-24].

Many scholars have carried out in-depth research on the crack growth, among which the research on the fatigue crack growth model will directly affect the accuracy of calculation and prediction [25-27]. The crack growth prediction models could roughly divide into two categories: one is the relationship between material parameters and crack growth rate with static parameters and the other is the energy parameter. When the cumulative damage of the surrounding microelements reaches a certain critical point, the crack will expand forward. The crack in the wall of the tank is produced after plastic deformation, which is often related to the pressure on the tank. When the pressure is small, the wall of the tank will produce elastic deformation and no fatigue crack will occur at this time. When the pressure reaches the yield limit of the material of the wall, the plastic deformation will occur on the tank wall, and the fatigue crack will form slowly.

Fatigue fracture is a common failure form of pressure bearing parts of the liquid-storage tank. Although the pressure does not reach the yield limit of the material, fatigue cracks will still occur on the surface of the parts [28]. For the cylindrical vessel, due to the hydrostatic pressure of the liquid, hoop stress shown in Figure 3 will be generated on the surface of the wall of the tank. Because of the effect of hoop stress, the strength of the tank wall will gradually decrease and produce cracks, leading to fatigue failure of vessel $[29,30]$. Additional bending stress will be produced under the action of wind, and machining residual stress will be produced in the metal due to machining deformation. Some of these stresses are constant, and some are evenly distributed along the wall thickness. Their effects on the components are different. Here, the research object is the wall of the tank, and only the hoop stress caused by hydrostatic pressure is considered. Table 4 shows the tank 


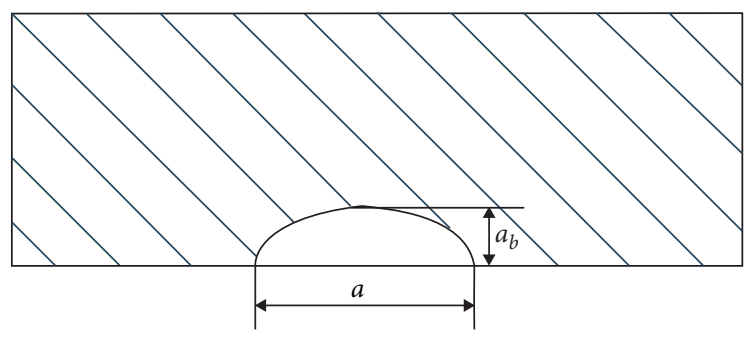

Figure 1: Schematic diagram of crack surface length and depth.

TABle 1: Tensile round bar test data.

\begin{tabular}{|c|c|c|c|c|c|c|c|c|}
\hline \multicolumn{8}{|c|}{$\Delta P(159 \mathrm{MPa})$} & \multirow{3}{*}{$\frac{\text { Deviation of } a_{b}}{1.70}$} \\
\hline \multirow{2}{*}{ No.1 } & $a_{b}(\mathrm{~mm})$ & 2.16 & 3.03 & 3.52 & 4.05 & 4.24 & 6.37 & \\
\hline & $N\left(10^{4}\right)$ & 0 & 9.60 & 17.10 & 20.10 & 22.40 & 24.70 & \\
\hline \multirow{2}{*}{ No.2 } & $a_{b}(\mathrm{~mm})$ & 1.52 & 3.12 & 3.42 & 3.87 & 6.53 & & 2.64 \\
\hline & $N\left(10^{4}\right)$ & 0 & 10.60 & 14.30 & 22.00 & 27.60 & & \\
\hline \multirow{2}{*}{ No.3 } & $a_{b}(\mathrm{~mm})$ & 1.84 & 2.97 & 3.47 & 3.87 & 6.75 & & 2.67 \\
\hline & $N\left(10^{4}\right)$ & 0 & 9.00 & 15.60 & 20.0 & 34.70 & & \\
\hline \multirow{2}{*}{ No.4 } & $a_{b}(\mathrm{~mm})$ & 2.22 & 3.04 & 3.65 & 4.20 & 6.43 & & 2.02 \\
\hline & $N\left(10^{4}\right)$ & 0 & 10.10 & 16.80 & 21.80 & 30.70 & & \\
\hline \multirow{2}{*}{ No.5 } & $a_{b}(\mathrm{~mm})$ & 2.38 & 3.24 & 3.58 & 4.09 & 4.43 & & 0.51 \\
\hline & $N\left(10^{4}\right)$ & 0 & 12.50 & 17.10 & 21.60 & 24.30 & & \\
\hline
\end{tabular}

TABLe 2: Theoretical data of tensile round bar (nonlinear model).

\begin{tabular}{lcccccc}
\hline \multicolumn{7}{c}{$\Delta P(159 \mathrm{MPa})$} \\
\hline \multirow{2}{*}{ No. 1} & $a_{b}(\mathrm{~mm})$ & 2.16 & 3.03 & 3.52 & 4.05 & 4.24 \\
& $N\left(10^{4}\right)$ & 0 & 8.80 & 12.30 & 15.50 & 16.50 \\
\hline \multirow{2}{*}{ No. 2} & $a_{b}(\mathrm{~mm})$ & 1.52 & 3.12 & 3.42 & 3.87 & 6.53 \\
& $N\left(10^{4}\right)$ & 0 & 19.70 & 21.90 & 24.70 & 35.40 \\
\hline \multirow{2}{*}{ No. 3 } & $a_{b}(\mathrm{~mm})$ & 1.84 & 2.97 & 3.47 & 3.87 & 6.75 \\
& $N\left(10^{4}\right)$ & 0 & 12.80 & 16.50 & 19.00 & 30.20 \\
\hline \multirow{2}{*}{ No. 4} & $a_{b}(\mathrm{~mm})$ & 2.22 & 3.04 & 3.65 & 4.20 & 6.43 \\
& $N\left(10^{4}\right)$ & 0 & 8.10 & 12.40 & 15.50 & 24.10 \\
\multirow{2}{*}{ No. 5 } & $a_{b}(\mathrm{~mm})$ & 2.38 & 3.24 & 3.58 & 4.09 & 4.43 \\
& $N\left(10^{4}\right)$ & 0 & 7.70 & 10.10 & 13.10 & 14.80 \\
\hline
\end{tabular}

TABLE 3: Theoretical data of tensile round bar (linear model).

\begin{tabular}{lccccccc}
\hline \multicolumn{7}{c}{$\Delta P(159 \mathrm{MPa})$} \\
\hline \multirow{2}{*}{ No. 1 } & $a_{b}(\mathrm{~mm})$ & 2.16 & 3.03 & 3.52 & 4.05 & 4.24 & 6.37 \\
& $N\left(10^{4}\right)$ & 0 & 6.40 & 9.20 & 11.60 & 12.40 & 18.90 \\
\hline \multirow{2}{*}{ No. 2 } & $a_{b}(\mathrm{~mm})$ & 1.52 & 3.12 & 3.42 & 3.87 & 6.53 & \\
& $N\left(10^{4}\right)$ & 0 & 14.30 & 16.00 & 18.10 & 26.60 & \\
\hline \multirow{2}{*}{ No. 3 } & $a_{b}(\mathrm{~mm})$ & 1.84 & 2.97 & 3.47 & 3.87 & 6.75 & \\
& $N\left(10^{4}\right)$ & 0 & 9.40 & 12.20 & 14.10 & 23.00 & \\
\hline \multirow{2}{*}{ No. 4 } & $a_{b}(\mathrm{~mm})$ & 2.22 & 3.04 & 3.65 & 4.20 & 6.43 & \\
& $N\left(10^{4}\right)$ & 0 & 6.00 & 9.30 & 11.70 & 18.50 & \\
\hline \multirow{2}{*}{ No. 5 } & $a_{b}(\mathrm{~mm})$ & 2.38 & 3.24 & 3.58 & 4.09 & 4.43 & \\
& $N\left(10^{4}\right)$ & 0 & 5.80 & 7.60 & 9.90 & 11.20 & \\
\hline
\end{tabular}

parameters. And the stress diagram of the wall of the tank is shown in Figure 3.

In Figure 3, $\sigma$ is the hoop stress, and $\sigma=(q R / t) . R$ is the radius of the cylinder, and $t$ is the thickness of the cylinder. $q=\rho g h$, where $q$ is the hydrostatic pressure. $\rho$ is the density of liquid, $g$ is the acceleration of gravity, and $h$ is the depth of liquid. The tank has been in service for about 10 years.

Actually, most of the liquid-storage tanks have been treated with anticorrosion to reduce the impact of chemical raw materials and extend their service life. In addition, most of the impurities sink into the bottom of the tank, and the most serious part of the tank corrosion is the bottom of the tank [8]. In this manuscript, the life prediction is based on the cracks of the tank wall. Therefore, the influence of corrosion on the life prediction is not considered here.

Table 5 shows the detection data of the first and second layers of the storage tank, and the defect location is shown with the $T$-shaped port in Figure 4.

For the smooth specimen, its fatigue life is mainly composed of crack initiation life. In the tank, the hoop stress level is high. As the crack initiation life is a part of the total life, the crack propagation life plays a significant role. 


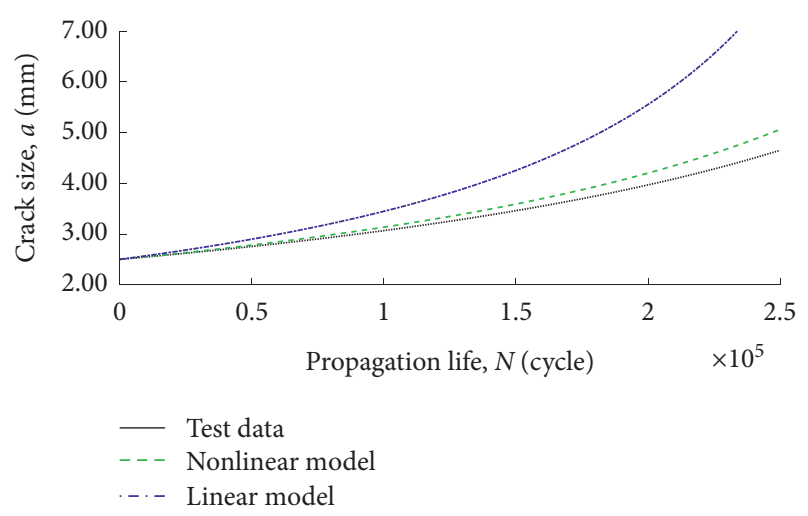

Figure 2: Relationship between crack depth and crack growth life.

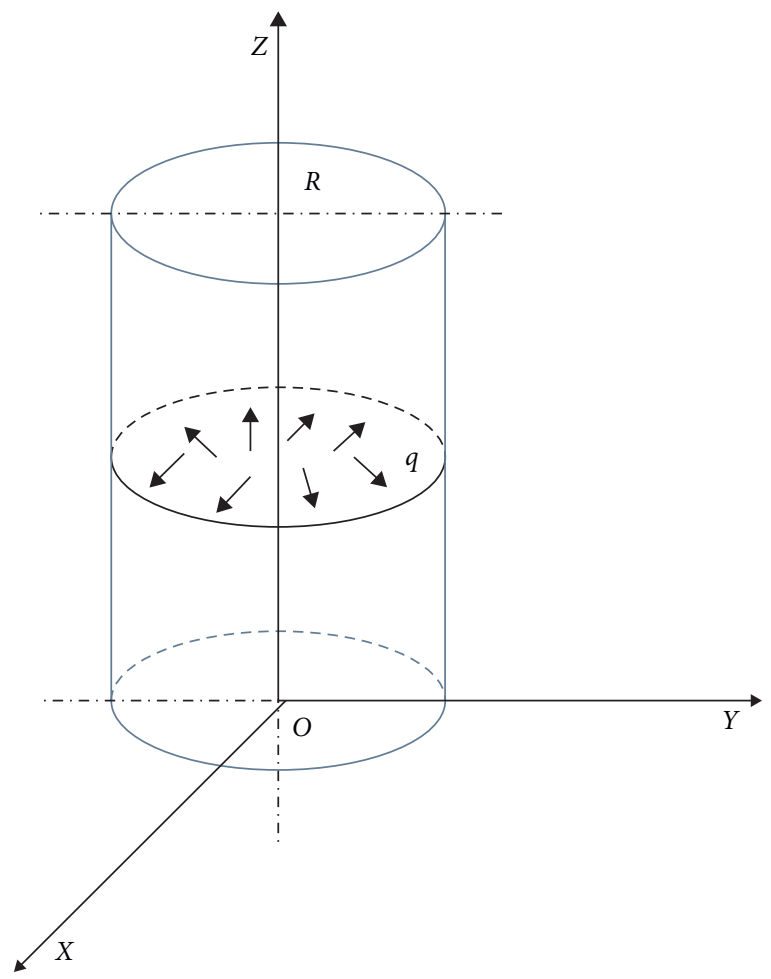

FIGURE 3: Schematic diagram of circumferential stress of the cylinder.

TABle 4: Parameters of liquid-storage tank.

\begin{tabular}{lcc}
\hline Size $(\mathrm{mm})$ & Storage media & Material \\
\hline$\Phi 28000 \times 20907$ & Gas & Gr 60 \\
\hline
\end{tabular}

Through practical observation, the failure of the pressure vessel often occurs at the defect.

Figures 5 and 6 are the measured figures of no. 10 and no. 12 cracks, respectively.

According to reference [31], set the high and low liquid level cycle period as 5 days. And the theoretical service year of the tank is shown in Table 6. It can be seen that the total
TABLE 5: Crack defect parameters.

\begin{tabular}{lc}
\hline Defect location & Crack size $(\mathrm{mm})$ \\
\hline $1-3$ & 7 \\
$1-13$ & 20 \\
\hline
\end{tabular}

\begin{tabular}{|c|c|c|c|c|c|c|c|c|c|c|c|c|c|}
\hline $2-2$ & \multicolumn{2}{|c|}{$2-1$} & \multicolumn{2}{c|}{$2-8$} & $2-7$ & $2-6$ & $2-5$ & $2-4$ & $2-3$ \\
\hline $1-2$ & $1-1$ & $1-14$ & $1-13$ & $1-12$ & $1-11$ & $1-10$ & $1-9$ & $1-8$ & $1-7$ & $1-6$ & $1-5$ & $1-4$ & $1-3$ \\
\hline
\end{tabular}

Figure 4: Crack defect location.

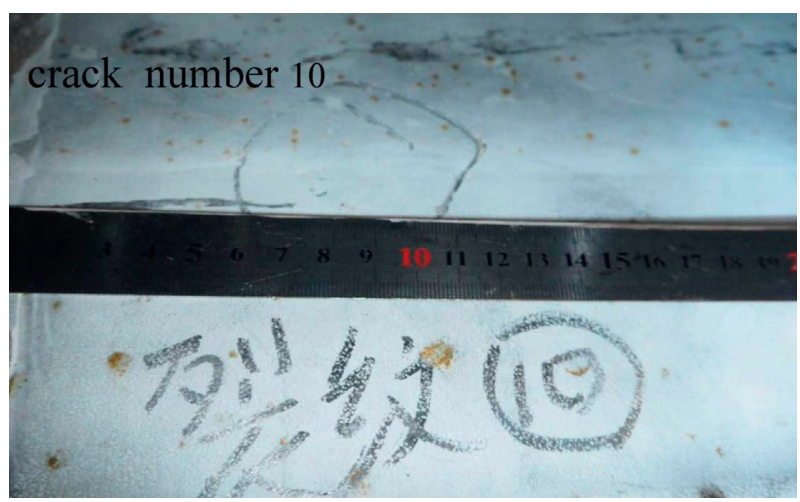

Figure 5: Actual measurement of crack no. 10.

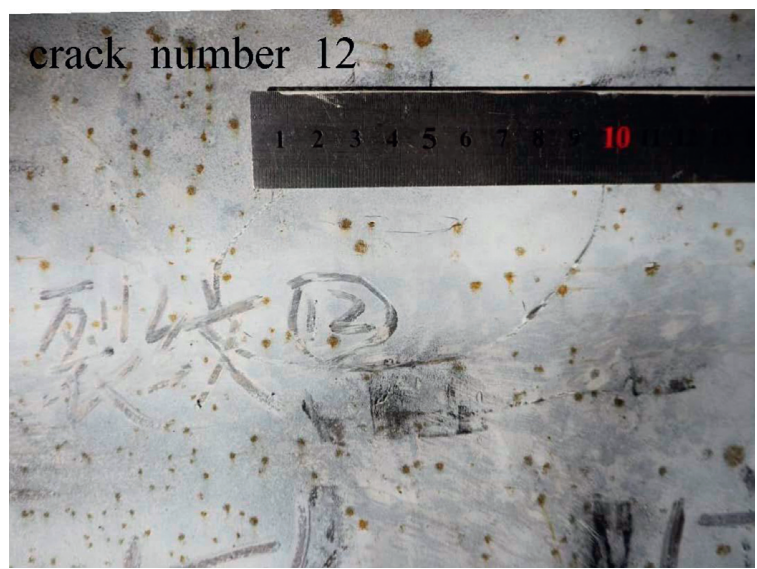

Figure 6: Actual measurement of crack no. 12.

TABle 6: Service life of the first and second layers.

\begin{tabular}{lccc}
\hline $\begin{array}{l}\text { Initial size } \\
(\mathrm{mm})\end{array}$ & $\begin{array}{c}\text { Critical size } \\
(\mathrm{mm})\end{array}$ & $\begin{array}{c}\text { Propagation life } \\
(\text { cycle })\end{array}$ & $\begin{array}{c}\text { Service time } \\
\text { (year) }\end{array}$ \\
\hline 7 & 20 & 674 & 9.2 (service life) \\
20 & 1223 & 697 & $\begin{array}{c}9.5 \text { (remaining } \\
\text { life) }\end{array}$ \\
\hline
\end{tabular}

theoretical service life of the tank is about 20 years, which is consistent with the design service life of the tank.

\section{Conclusions}

In this paper, the relationship between crack length and crack depth is explored based on the Paris law. And the 
lifetime of the liquid-storage tank is predicted by the numerical model. Then, the following conclusions could be drawn:

(1) The relationship between fatigue crack length and crack depth is studied, and the lifetime data of round bar with linear and nonlinear models are obtained. The results show that the nonlinear model is more suitable for describing the relationship between crack length and depth.

(2) The rationality of the model is verified by the prediction of the service time of the tank. The remaining life of the tank is obtained by a numerical model, which is consistent with the actual service condition.

(3) Considering the effect of crack size on the fatigue life of the tank, the critical size of the crack is obtained. It is found that crack depth is related to the fatigue life, which provides a new numerical method for the liquid-storage tank life prediction.

\section{Data Availability}

Data sharing is not applicable to this article as no new data were created or analyzed in this study.

\section{Conflicts of Interest}

The authors declare that they have no conflicts of interest.

\section{Acknowledgments}

This work was supported by the Key R\&D Plan of Guangxi Science and Technology Planned Projects (GKAB18294005), the Basic Ability Enhancement Program for Young- and Middle-Aged Teachers of Guangxi (2018KY0603), the Qinzhou Science and Technology Planned Projects (20198515), and the Beibu Gulf University High-Level Talent Foundation (2018KYQD26).

\section{References}

[1] W. Meng, Q. G. Fei, and P. W. Zhang, "A modified fatigue damage model for high-cycle fatigue life prediction," Advances in Materials Science \& Engineering, vol. 2016, Article ID 2193684, 7 pages, 2016.

[2] H. L. Wang and S. F. Qin, "High-strength bolt corrosion fatigue life model and application," Scientific World Journal, vol. 2014, Article ID 567318, 5 pages, 2014.

[3] M. Zhang, X. Liu, Y. Wang, and X. Wang, "Parameter distribution characteristics of material fatigue life using improved bootstrap method," International Journal of Damage Mechanics, vol. 28, no. 5, pp. 772-793, 2019.

[4] H. Wang, X. Liu, X. Wang, and Y. Wang, "Numerical method for estimating fatigue crack initiation size using elastic-plastic fracture mechanics method," Applied Mathematical Modelling, vol. 73, pp. 365-377, 2019.

[5] F. Kan, X. Liu, X. Xin, J. Xu, H. Huang, and Y. Wang, "Analysis and evaluation of the leakage failure for clutch sleeve and shell," Engineering Failure Analysis, vol. 88, pp. 1-12, 2018.
[6] Y. H. Li, P. P. Zhi, Y. Zhang, B. Z. Chen, and Y. D. Wang, "Fatigue reliability analysis of motor hanger for high-speed train based on Bayesian updating and subset simulation," Advances in Materials Science and Engineering, Vol. 2020, Article ID 3012471, 2020, in press.

[7] S. P. Zhu, Q. Liu, J. Zhou, and Z. Y. Yu, "Fatigue reliability assessment of turbine discs under multi-source uncertainties," Fatigue \& Fracture of Engineering Materials \& Structures, vol. 41, no. 6, pp. 1291-1305, 2018.

[8] M. G. Ji and C. Y. Zhou, "Corrision fatigue crack propagation experimental investigation for butt joint of $12 \mathrm{MnNiVR}$ steel used for large oil tank," Pressure Vessel Technology, vol. 25, no. 4, pp. 1-4, 2018.

[9] Y.-J. Lee, H. Ahmed, and J.-R. Lee, "Filament-wound composite pressure vessel inspection based on rotational throughtransmission laser ultrasonic propagation imaging," Composite Structures, vol. 236, Article ID 111871, 2020.

[10] A. R. Casha, L. Camilleri, M. Gauci et al., "A mathematical model for pressure-based organs behaving as biological pressure vessels," Journal of Theoretical Biology, vol. 450, pp. 37-42, 2018.

[11] A. Strozzi, E. Bertocchi, and S. Mantovani, "Analysis of a segmented locking ring for shell-bottom connection in pressure vessels," Materials Today: Proceedings, vol. 5, no. 13, pp. 26766-26771, 2018.

[12] U. Shafiq, A. M. Shariff, M. Babar, B. Azeem, A. Ali, and M. A. Bustam, "A review on modeling and simulation of blowdown from pressurized vessels and pipelines," Process Safety and Environmental Protection, vol. 133, pp. 104-123, 2020.

[13] J. Schijve, Fatigue of Structures and Materials, Springer, Berlin, Germany, 2008.

[14] Z. You, X. Liu, Z. Jiang, X. Wang, Y. Wang, and X. Wang, "Numerical method for fatigue life of aircraft lugs under thermal stress," Journal of Aircraft, vol. 57, no. 4, pp. 597-602, 2020.

[15] X. Liu, M. Zhang, H. Wang, J. Luo, J. Tong, and X. Wang, "Fatigue life analysis of automotive key parts based on improved peak-over-threshold method," Fatigue \& Fracture of Engineering Materials \& Structures, vol. 43, no. 8, pp. 18241836, 2020.

[16] S. C. Wang, X. T. Liu, C. J. Jiang, X. Wang, and X. L. Wang, "Prediction and evaluation of fatigue life for mechanical components considering anelasticity-based load spectrum," Fatigue \& Fracture of Engineering Materials \& Structures, 2020.

[17] B. Li, Z. Wang, K. Wei et al., "Evaluation of helium effect on irradiation hardening in F82H, ODS, SIMP and T91 steels by nano-indentation method," Fusion Engineering and Design, vol. 142, pp. 6-12, 2019.

[18] X. Liu, K. Mao, X. Wang, X. Wang, and Y. S. Wang, “A modified quality loss model of service life prediction for products via wear regularity," Reliability Engineering \& System Safety, vol. 204, Article ID 107187, 2020.

[19] Z. S. Zhang and S. C. Yan, "Surface crack growth rule of 921A steel welded joint under corrosion fatigue," Journal of Huazhong University of Technology, vol. 2, no. 6, pp. 37-41, 1992, in Chinese.

[20] H. J. Tian, Experimental Study and Finite Element Analysis of Surface Cracks in Sucker Rods, Northeastern University, Boston, MA, USA, 2010, in Chinese.

[21] Y. T. Li and Y. Y. Zhang, "The growth rule of surface crack in pressure vessel under high cycle fatigue," Journal of Lanzhou 
University of Technology, vol. 41, no. 176(6), pp. 174-178, 2015, in Chinese.

[22] J. J. Xiao and J. Jian, "Stress analysis and structure optimization for the opening flat cover of pressure vessels," $A d$ vanced Materials Research, vol. 538-541, pp. 3253-3258, 2012.

[23] J. D. Fishburn, "A single technically consistent design formula for the thickness of cylindrical sections under internal pressure," Journal of Pressure Vessel Technology, vol. 129, no. 1, pp. 211-215, 2007.

[24] K. Lu, J. Katsuyama, and Y. S. Li, "Improvements on evaluation functions of a probabilistic fracture mechanics analysis code for reactor pressure vessels," Journal of Pressure Vessel Technology, vol. 142, no. 2, 2019, in press.

[25] H. J. Wang, X. T. Liu, M. H. Zhang, Y. S. Wang, and X. L. Wang, "Prediction of material fatigue parameters for low alloy forged steels considering error circle," International Journal of Fatigue, vol. 121, pp. 135-145, 2017.

[26] X. Liu, F. Kan, H. Wang, X. Xin, Z. Wang, and H. Huang, "Fatigue life prediction of clutch sleeve based on abrasion mathematical model in service period," Fatigue \& Fracture of Engineering Materials \& Structures, vol. 43, no. 3, pp. 488-501, 2020.

[27] M. Wang, X. Liu, X. Wang, and Y. Wang, "Probabilistic modeling of unified S-N curves for mechanical parts," International Journal of Damage Mechanics, vol. 27, no. 7, pp. 979-999, 2018.

[28] S.-P. Zhu, H.-Z. Huang, W. Peng, H.-K. Wang, and S. Mahadevan, "Probabilistic physics of failure-based framework for fatigue life prediction of aircraft gas turbine discs under uncertainty," Reliability Engineering \& System Safety, vol. 146, pp. 1-12, 2016.

[29] R. J. Merino, E. Brunesi, and R. Nascimbene, "Probabilistic evaluation of earthquake-induced sloshing wave height in above-ground liquid storage tanks," Engineering Structures, vol. 202, 2020 In press, Article ID 109870.

[30] Z. Y. You, Y. Fang, X. T. Liu et al., "Numerical method for fatigue life of plane bolted joints under thermal load," Proceedings of the Institution of Mechanical Engineers Part G Journal of Aerospace Engineering, 2020, In press.

[31] F. Yang, C. Y. Fu, C. Zhang, and T. H. Chen, "Calculation analysis on inner tank design life of large liquefied natural gas tank," Petrochemical Equipment, vol. 43, no. 6, pp. 46-49, 2014, in Chinese. 